\title{
Pulmonary rehabilitation principles in SARS-COV-2 infection (COVID-19): The revised guideline for the acute, subacute, and post-COVID-19 rehabilitation
}

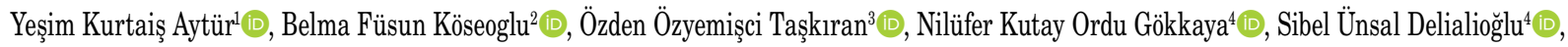



 \\ Öznur Öken ${ }^{13} \mathbb{D}$, Hande Özdemir ${ }^{11} \mathbb{D}$, Feray Soyupek ${ }^{14}\left(\mathbb{D}\right.$, Canan Tıkız ${ }^{15}(\mathbb{D}$
}

${ }^{1}$ Department of Physical Medicine and Rehabilitation, Ankara University, Faculty of Medicine, Ankara, Turkey

${ }^{2}$ Department of Physical Medicine and Rehabilitation, TOBB University of Economy and Technology, Faculty of Medicine, Ankara, Turkey

${ }^{3}$ Department of Physical Medicine and Rehabilitation, Koç University, School of Medicine, Istanbul, Turkey

${ }^{4}$ Department of Physical Medicine and Rehabilitation, Republic of Turkey Ministry of Health, University of Health Sciences, Ankara City Hospital Health Application and Research Center, Ankara, Turkey

${ }^{5}$ Department of Physical Medicine and Rehabilitation, Zonguldak Bülent Ecevit University, School of Medicine, Zonguldak, Turkey

${ }^{6}$ Department of Physical Medicine and Rehabilitation, Private Liv Hospital, Istanbul, Turkey

'Department of Physical Medicine and Rehabilitation, Atllım University, School of Medicine, Medicana International Hospital, Ankara, Turkey

${ }^{8}$ Department of Physical Medicine and Rehabilitation, Republic of Turkey Ministry of Health, University of Health Sciences, Gülhane School of Medicine, Ankara Training and Research Hospital, Ankara, Turkey

${ }^{9}$ Department of Physical Medicine and Rehabilitation, Republic of Turkey Ministry of Health, University of Health Sciences, Gülhane School of Medicine, Ankara Dışkapı Ylldırım Beyazit Training and

Research Hospital, Ankara, Turkey

${ }^{10}$ Department of Physical Medicine and Rehabilitation, Çukurova University Faculty of Medicine, Adana, Turkey

${ }^{11}$ Department of Physical Medicine and Rehabilitation, Trakya University School of Medicine, Edirne, Turkey

${ }^{12}$ Department of Physical Medicine and Rehabilitation, Republic of Turkey Ministry of Health, Erenköy Physical Medicine and Rehabilitation Hospital, Istanbul, Turkey

${ }^{13}$ Department of Physical Medicine and Rehabilitation, Ankara Liv Hospital, Ankara, Turkey

${ }^{14}$ Department of Physical Medicine and Rehabilitation, Isparta Süleyman Demirel University, School of Medicine, Isparta, Turkey

${ }^{15}$ Department of Physical Medicine and Rehabilitation, Manisa Celal Bayar University, School of Medicine, Manisa, Turkey

Received: April 21, 2021 Accepted: May 10, 2021 Published online: May 25, 2021

\begin{abstract}
Coronavirus disease 2019 (COVID-19) is a contagious infection disease, which may cause respiratory, physical, psychological, and generalized systemic dysfunction. The severity of disease ranges from an asymptomatic infection or mild illness to mild or severe pneumonia with respiratory failure and/or death. COVID-19 dramatically affects the pulmonary system. This clinical practice guideline includes pulmonary rehabilitation (PR) recommendations for adult COVID-19 patients and has been developed in the light of the guidelines on the diagnosis and treatment of COVID-19 provided by the World Health Organization and Republic of Turkey, Ministry of Health, recently published scientific literature, and PR recommendations for COVID-19 regarding basic principles of PR. This national guideline provides suggestions regarding the PR methods during the clinical stages of COVID-19 and post-COVID-19 with its possible benefits, contraindications, and disadvantages.
\end{abstract}

Keywords: COVID-19, guideline, post-COVID-19, pulmonary rehabilitation, severe acute respiratory syndrome.

Corresponding author: Sibel Ünsal Delialioglu, MD. Ankara Şehir Hastanesi, Fizik Tedavi ve Rehabilitasyon Kliniği, 06800 Çankaya, Ankara, Türkiye.

e-mail: sibelunsal74@yahoo.com

Cite this article as:

Kurtaiş Aytür Y, Köseoglu BF, Özyemişci Taşkıran 0̈, Kutay Ordu Gökkaya N, Ünsal Delialioğlu S, Sonel Tur B, et al. Pulmonary rehabilitation principles in SARS-COV-2 infection (COVID-19): The revised guideline for the acute, subacute, and post-COVID-19 rehabilitation. Turk J Phys Med Rehab 2021;67(2):129-145.

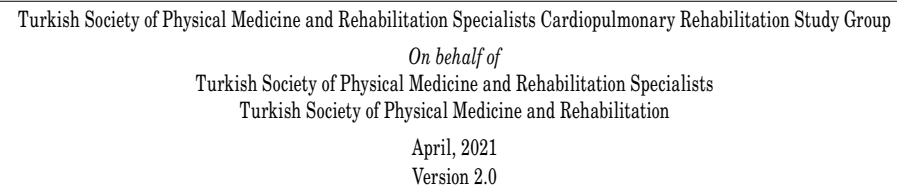


Coronavirus disease 2019 (COVID-19) is caused by severe acute respiratory syndrome-coronavirus-2 (SARS-CoV-2), a newly emergent coronavirus, that was first recognized in Wuhan, China, in December 2019. ${ }^{[1]}$ The first case in Turkey was identified on March $11^{\text {th }}, 2020 .^{[2]}$ The World Health Organization (WHO) declared COVID-19 as a pandemic on March $12^{\text {th }}, 2020 .{ }^{[3]}$

SARS-CoV-2 is a beta-coronavirus with a genetic sequence highly similar to SARS virus. ${ }^{[3]}$ Angiotensinconverting enzyme 2 (ACE-2) found in the lower respiratory airways of humans is a cellular receptor for SARS-CoV and has been shown to play a role in the spread from one human being to another and in crosstransmission. ${ }^{[4,5]}$ The ACE-2 is mainly associated with cardiovascular diseases and it is a type I membrane protein expressed by the lungs, heart, kidneys, and bowel. ${ }^{[6]}$

While most individuals with COVID-19 develop only mild $(40 \%)$ or moderate $(40 \%)$ disease, approximately $15 \%$ develop severe disease which requires oxygen support, and $5 \%$ have critical disease with complications such as respiratory failure, acute respiratory distress syndrome (ARDS), sepsis and septic shock, thromboembolism, and/or multi-organ failure, including acute kidney injury and cardiac injury (Tables 1,2$) \cdot{ }^{[3]}$

Elderly individuals and individuals with underlying health conditions (diabetes, hypertension, cardiac disease, chronic lung, kidney and hepatic disease, obesity and cancer) are more prone to infection and more inclined to ARDS and severe consequences that may be related to cytokine storms. ${ }^{[7,8]}$ Among hospitalized COVID-19 patients, approximately 33\% develop ARDS, $26 \%$ require transfer to an intensive care unit (ICU), $16 \%$ receive invasive mechanical ventilation (IMV), and $16 \%$ die. ${ }^{[9]}$

As in cases of ARDS due to other causes, age and comorbid disease states are reported as risk factors for COVID-19, as well. In multivariate analysis, advanced age, a high Sequential Organ Failure Assessment (SOFA) score, and an elevated D-dimer level at the time of admission were associated with higher mortality. ${ }^{[3]}$ In COVID-19, the mortality rate was reported as $40 \%$ in patients admitted to ICU, $59 \%$ of those who received IMV, and 45\% in COVID-19-associated ARDS. ${ }^{[9]}$

Autopsies were performed in 10 African American decedents aged 44 to 78 years with a cause of death attributed to COVID-19. Important findings included the presence of thrombosis and microangiopathy in the small vessels and capillaries of the lungs, with associated hemorrhage, that significantly contributed to death. Pathological features of diffuse alveolar damage including hyaline membranes were reported even in patients who had not been on IMV. There were also cardiac findings, such as individual cell necrosis without lymphocytic myocarditis. ${ }^{[10]}$

The long-term sequelae of COVID-19 are still unknown. Lessons from past viral epidemics reveal that, after recovery, patients with viral pulmonary infections can suffer from irreversible pulmonary dysfunction and demonstrate residual imaging or functional abnormalities. Residual ground-glass opacities, consolidations, reticular and linear opacities,

TABLE 1

Symptoms and risk factors associated with COVID $-19^{9^{13}}$

Clinical presentation

Risk factors for severe disease
Presenting signs and symptoms of COVID-19.

Fever (83-99\%), cough (59-82\%), fatigue (44-70\%), anorexia (40-84\%), shortness of breath (31-40\%), myalgia (11-35\%).

Other non-specific symptoms; sore throat, nasal congestion, headache, diarrhea, nausea, vomiting, loss of smell (anosmia) or loss of taste (ageusia). ${ }^{[1,62-67]}$

Older people and immunosuppressed patients in particular may present with atypical symptoms such as fatigue, reduced alertness, reduced mobility, diarrhea, loss of appetite, delirium, and absence of fever. ${ }^{[68-70]}$ In pregnant women, symptoms such as dyspnea, fever, gastrointestinal (GI) symptoms or fatigue due to physiologic adaptations, adverse pregnancy events, or other diseases such as malaria, may overlap with symptoms of COVID-19 ${ }^{[71]}$

Children might not experience fever or cough as frequently as adults ${ }^{[72]}$

Age older than 60 years (increasing with age).

Underlying non-communicable diseases (NCDs): diabetes, hypertension, cardiac disease, chronic lung disease, cerebrovascular disease, chronic kidney disease, immunosuppression and cancer have been associated with higher mortality.

Smoking. 




residual crazy paving pattern, melted sugar sign, and parenchymal fibrotic bands are typical features found in the late or remission stages of COVID-19. These radiological findings can be observed weeks after the symptom onset, even after hospital discharge, and they may or may not correlate with clinical manifestations. ${ }^{[1]}$

Currently, there is no specific antiviral drug for COVID-19. Although there is no approved antiviral regimen, drugs including lopinavir/ritonavir, remdesivir, favipiravir, umifenovir, emtricitabine, chloroquine and hydroxychloroquine, azithromycin, immunomodulators (i.e., tocilizumab, anakinra, interferon- $\beta-1 \mathrm{a}$ ), and plasma therapy are being used. ${ }^{[3]}$

As of March 2021, there are more than 300 vaccine candidates at different development stages. ${ }^{[12]}$ An efficacious vaccine is essential to prevent further morbidity and mortality. Several technological methods (e.g., DNA, RNA, inactivated, viral vector, protein subunit) are available for vaccine development. ${ }^{[13]}$ Vaccination has started in many countries worldwide with several different vaccines.

The guidelines by the Republic of Turkey, Ministry of Health define the patients complying with the diagnoses of pneumonia and severe pneumonia and the indications for admission to ICU for our country in detail. ${ }^{[14]}$

As there is no adequate data about the longterm results, the degree of damage or sequela after the active disease is not known. Being the main target, respiratory system seems to be one of the most vulnerable systems for the unforeseen damage or sequela. This situation requires a good planning of post-COVID-19 management in the long-term setting, including pulmonary rehabilitation (PR).

In a patient-specific manner, $P R$ is planned based on a detailed patient assessment including but not limited to training, exercise, and behavioral 
changes, since it aims at improving the physical and psychological status of individuals with chronic respiratory disease and focuses on comprehensive interventions for long-term commitment to health improvement attitudes. ${ }^{[15]}$ Although PR has classically been defined for the treatment of chronic pulmonary diseases, it is also needed and implemented during the course of different pulmonary diseases and during immobility, surgery, and systemic, neurological, and musculoskeletal diseases which impair breathing.

Pulmonary rehabilitation procedures will definitely be necessary for the right patient at the right time. ${ }^{[16-18]}$ In patients with COVID-19 pneumonia or ARDS, multidisciplinary and holistic approach in COVID-19 management encompasses the PR with the selection of appropriate components according to the individual needs. Although indications of PR specific to COVID-19 are not clear, general indications can be listed as follows, when the effects of the disease on the respiratory system and its consequences are taken into consideration:

1. During the acute disease, dyspnea, cough, difficulty in expectoration, respiratory failure, gas exchange abnormalities and immobility

2. Difficulty in daily life activities due to decreased functional status

3. Nutritional deficiency

4. Deterioration in quality of life

5. Psychosocial problems

6. Fatigue and chronic respiratory symptoms in the long term

7. Decrease in work performance

8. Increase in the utilization of medical resources such as hospital admission due to chronic respiratory problems secondary to COVID-19.

The scope of standard PR includes the following components:

1. Education of the patient, family or caregiver

2. Smoking cessation

3. Exercise training; respiratory and peripheral muscle training

4. Breathing strategies; bronchial hygiene techniques and breathing retraining

5. Occupational therapies

6. Nutritional evaluation and support

7. Psychosocial evaluation and support

8. Oxygen support
9. Utilization of non-invasive and invasive mechanical ventilation

Among the elements of $\mathrm{PR}$, exercise training is the most effective and compulsory method in achieving the goals of PR. Exercise and other rehabilitation approaches are demonstrated in Table 3.

\section{Protection}

The most important routes of transmission for COVID-19 between humans are close contact and droplet spread. Therefore, healthcare workers (HCWs) who provide service to these patients are regarded as having a high risk of transmission and the protection of HCWs is one of the most important priorities. There are guidelines issued by both $\mathrm{WHO}^{[3,19]}$ and the Republic of Turkey Ministry of Health ${ }^{[20]}$ concerning the use of personal protective equipment (PPE). According to these guidelines, HCWs having contact with possible/ confirmed COVID-19 patients have to use PPE appropriate for droplet, contact, and aerosolization type routes of transmission. For all the patients diagnosed with COVID-19, HCWs need to use surgical masks, gowns, gloves, goggles/shields during patient care/treatment. During procedures with the potential of aerosol transmission of the virus (respiratory tract sampling, close distance examinations, all types of invasive procedures, respiratory secretion aspirations, etc.) HCWs should definitely use particle-blocking masks (N95). In the guideline issued by the Republic of Turkey Ministry of Health, risk stratification has not been made for PR bronchial drainage techniques such as assisted coughing techniques, respiratory exercises, postural drainage and percussion. However, some of the published guidelines state that all these procedures will lead to aerosol production and that the HCW should definitely use an N95 mask. ${ }^{[21,22]}$ The HCWs should also respect the sequencing rules when donning/doffing of PPE.

\section{The Purpose of the Guideline}

This national guideline was prepared to inform primarily the physical medicine and rehabilitation (PMR) specialists and other physicians who follow COVID-19 patients. This guideline provides suggestions regarding the PR methods during the clinical stages of COVID-19 and post-COVID-19 with its possible benefits, contraindications and disadvantages.

\section{The Scope of the Guideline}

This guideline is prepared in the light of COVID-19 diagnosis and treatment guidelines of WHO and the Republic of Turkey, Ministry of Health, Public Health General Directorate, ${ }^{[3,18]}$ of published articles 


\begin{tabular}{|c|c|}
\hline & $\begin{array}{l}\text { TABLE } 3 \\
\text { Exercise components of pulmonary rehabilitation }\end{array}$ \\
\hline Respiratory muscle training & $\begin{array}{l}\text { a. Inspiratory muscle training: } \\
\text { - Voluntary isocapnic hyperpnea or normocapnic hyperventilation } \\
\text { - Inspiratory resistive loading } \\
\text { - Inspiratory threshold loading } \\
\text { - Tapered threshold loading } \\
\text { b. Expiratory muscle training }\end{array}$ \\
\hline Breathing strategies & $\begin{array}{l}\text { a. Controlled breathing techniques } \\
\text { - Pursed lip breathing } \\
\text { - Segmental breathing (lateral costal breathing) } \\
\text { - Diaphragmatic breathing (abdominal breathing) } \\
\text { - Slow and deep breathing } \\
\text { - Alternate nostril breathing } \\
\text { - Frog breathing (Glossopharyngeal breathing) } \\
\text { - Head-down (Trendelenburg) and bending forward postures } \\
\text { - Abdominal girdle } \\
\text { - Relaxation exercises } \\
\text { b. Bronchial hygiene-airway clearance techniques } \\
\text { - Forced expiration techniques } \\
\text { ○ Controlled cough maneuver } \\
\text { - Huffing } \\
\text { - Incentive spirometry (sustained maximal inspiration-SMI) } \\
\text { - Postural drainage, percussion, vibration } \\
\text { - Positive expiratory pressure (PEP) } \\
\text { - Active cycle of breathing techniques (ACBT) } \\
\text { - Autogenic drainage } \\
\text { - Mechanical Insufflator-Exsufflator (MI-E) } \\
\text { - Intrapulmonary percussive ventilation (IPV) } \\
\text { - High-frequency chest wall oscillation (HFCWO) } \\
\text { - Cough increasing techniques } \\
\circ \text { Maximum Insufflation Capacity Maneuver (MIC) } \\
\text { - Glossopharyngeal breathing } \\
\text { ○ Manually assisted cough (MAC) } \\
\text { - MI-E and IPV }\end{array}$ \\
\hline Aerobic/endurance & $\begin{array}{l}\text { - Continuous/intermittent training } \\
\text { - Bicycle with a single leg } \\
\text { - Scandinavian/Nordic walking training } \\
\text { - Non-assisted walking training }\end{array}$ \\
\hline \multicolumn{2}{|l|}{ Strengthening/resistance } \\
\hline Other & $\begin{array}{l}\text { Upper extremity and shoulder girdle exercises } \\
\text { Exercises in water } \\
\text { Balance training } \\
\text { Neuromuscular electrical stimulation (NMES): (the diaphragm, abdominal muscles and extremity muscles) } \\
\text { Nonlinear exercise training } \\
\text { Whole-body vibration } \\
\text { Yoga training } \\
\text { Tai Chi exercises }\end{array}$ \\
\hline
\end{tabular}

on COVID-19 treatment and published expert opinion recommendations on PR for COVID-19. It contains recommendations for adult patients. The guideline includes PR recommendations for different clinical presentations of COVID-19 and prolonged symptoms and impairments after COVID-19 to help patients recover the disease. At the time of establishment of these recommendations, the transmissibility of
COVID-19, the principle of a limited number of HCWs having contact with the patient and the level of benefits to be provided by PR were taken into account.

\section{Method for Guideline Development}

For the purpose of developing a PR guideline to be used in the treatment of COVID-19 patients, PMR specialists who are experienced in the field of 
cardiopulmonary rehabilitation were invited to work together under the coordination of the Cardiopulmonary Rehabilitation Study Group of Turkish Society of Physical Medicine and Rehabilitation Specialists. The same group published the "Pulmonary Rehabilitation after COVID-19" short guideline on March $25^{\text {th }}, 2020$, as an expert opinion. ${ }^{[23]}$ Following this quick and brief guideline, preparation of a more detailed PR clinical practice guideline was decided on March $30^{\text {th }}$, 2020. The Turkish Society of Physical Medicine and Rehabilitation and Turkish Society of Physical Medicine and Rehabilitation Specialists together prepared the guideline and Cardiopulmonary Rehabilitation Study Group of the Turkish Society of Physical Medicine and Rehabilitation Specialists drafted the guideline on behalf of these two associations. ${ }^{[2]}$ Finally, the new version including PR recommendations for postCOVID-19 was developed. The steps listed below were followed in the preparation of the guideline:

1. AGREE II framework was followed in the development of the guideline. ${ }^{[25]}$

2. The literature search was conducted on PubMed, CINAHL, Google Scholar, Cochrane and related online databases. In the literature review, guidelines and recommendations during the last decade, meta-analyses, systematic reviews, randomized studies, and websites of relevant agencies such as WHO and the Republic of Turkey, Ministry of Health were analyzed. The language of the literature search was English. Furthermore, references translated into Turkish were used. Keywords were identified as "Coronavirus pneumonia", "Rehabilitation AND Coronavirus infection", "COVID-19", "SARS-CoV-2", "ARDS", "SARS", "MERS", "Influenza pneumonia", "Pulmonary rehabilitation AND Pneumonia", "Pulmonary rehabilitation after COVID-19", "Respiratory rehabilitation AND respiratory failure", "Rehabilitation AND Critically ill patient".

3. After all the participants reviewed the data obtained by this search, key research questions were prepared in accordance with the PICO framework. ${ }^{[26]}$ The prepared questions were individually reviewed by five of the authors (FK, NKOG, SÜD, TT, YKA), similar questions were combined and the questions were arranged for a common language and for the sake of clarity. The questions were tailored according to the Delphi technique and the final version was approved unanimously by the five-member group.
4. One hundred and ninety questions were prepared and sent to all the participants with the Qualtrics Program to be reviewed by the Delphi technique. In the light of scientific publications and personal experience, the participants were asked to mark each question as "Yes", "No" or "Do not know/ Neutral". The questions receiving more than $70 \%$ of the common view were approved as research questions and those receiving less than $70 \%$ of consensus were re-evaluated by the participants. In the second round, the questions approved with a rate of $65 \%$ were accepted as research questions.

5. Based on the results obtained from the research questions, six authors (BST, FK, NKOG, ÖÖT, SÜD, YKA) developed the recommendations.

6. For the post-COVID-19 recommendations, 38 questions were prepared and sent to all the participants with the Qualtrics Program to be reviewed by the Delphi technique. The same methodology explained in the $4^{\text {th }}$ item was applied for these questions.

7. The recommendations in the previous version ( $\mathrm{v}$ 1.1) were reviewed by all the authors. Six of the authors (BST, FK, NKOG, ÖÖT, SÜD, YKA) revised these recommendations considering the expert reviews, new knowledge and gained experience about COVID-19.

8. Finally, new recommendations and the final version of the guideline was presented for the approval of all the participants.

\section{RECOMMENDATIONS}

The vast majority of the literature data on the definition of PR and the effectiveness of different methods on mortality and morbidity are based on experiences in chronic pulmonary disease and mainly chronic obstructive pulmonary disease (COPD). There is still no literature with high-quality evidence about the use of PR for acute respiratory failure/ ARDS, COVID-19 and similar acute infectious conditions. Therefore, while preparing a PR guideline for COVID-19, there was a need to consider the characteristics of this disease and its transmissibility together with the results of other methods whose efficacy were investigated for chronic diseases to prioritize condition appropriate and individualized recommendations. In the preparation of the 
recommendations for $\mathrm{PR}$ applications, the following topics were emphasized:

- Recommendations for acute, post-acute, and post-COVID-19 stages of COVID-19 are presented.

- Each patient should be evaluated individually before PR. Evaluation methods may vary in a wide range from standard clinical examination to telemedicine and similar technological means, according to the patient's disease and transmission status and whether he/she is inpatient or at home. For the selected patients, individualized PR program is planned by the PMR specialist, regarding general rehabilitation principles and holistic approach.

- Given the fact that all types of rehabilitation practices entail high levels of transmission risk, rehabilitation services should be planned based on the isolation and protection principles, the source of PPE, the staff and infrastructure characteristics of the COVID-19 center. Due to similar concerns, rehabilitation services can also be provided through visual materials or telerehabilitation.

- Assessments requiring any equipment such as pulmonary function tests or cardiopulmonary exercise tests are not recommended in the acute and subacute phase, when there is a risk of contagiousness.

- Psychosocial and nutritional status of the patient should be taken into account, since all these may affect the outcome of PR intervention.

- Bronchial hygiene techniques, such as assisted cough, postural drainage and percussion, breathing exercises and mobilization that may induce cough, carry the risk of aerosolization and healthcare workers should wear appropriate PPE.

- Certain PR and general rehabilitation applications may lead to clinical deterioration by increasing respiratory workload in the acute COVID-19 infection. Rehabilitation programs should be individualized and closely monitored. Close communication with the primary physician of the patient about the clinical course is recommended.

- Other systemic involvements, particularly cardiac and neurological involvement secondary to COVID-19 should be taken into consideration, while planning the PR program.

- Patients and their families or caregivers should be educated regarding PR program.

- COVID-19 patients with severe lung involvement are expected to develop physical, functional, cognitive and psychosocial sequelae. It is important to organize rehabilitation programs to address these impairments.

- During all assessments and rehabilitation interventions, PPE complying with standard definitions of the Republic of Turkey, Ministry of Health should be used.

- COVID-19 survivors may report persistent restrictive ventilation deficits, regardless of disease severity; there is only sparse and lowquality evidence concerning the efficacy of any rehabilitation intervention to promote functional recovery.

\section{MILD DISEASE}

\section{RECOMMENDATION 1.1}

Comprehensive pulmonary rehabilitation in COVID-19 during the mild disease is not necessary, but relevant health measures should be taken into account.

Clinical symptoms are mild at this clinical condition. It is important that these individuals stay home and achieve a balance between rest and physical activity by paying attention to their symptoms. At a time when it is compulsory for these individuals to stay at home, indoor exercises such as marching on spot, joint range of motion (ROM), posture, balance and coordination exercises in conformity with the existent physical activity guidelines and criteria to symptom limit such as fatigue, dyspnea, dizziness etc. are suggested to refrain from adverse effects of physical activity restriction. ${ }^{[27,28]}$ During the mild disease, preventive measures such as cessation of smoking, sleep hygiene, nutritional balance, adequate fluid intake, and supportive measures recommended by the health authorities and guidelines should be taken. ${ }^{[29-34]}$

Individuals with special conditions (i.e., older age, immunocompromised, neurological, pulmonary, cardiovascular, musculoskeletal, metabolic or other systemic diseases) can be evaluated by a PMR specialist and their rehabilitation program should be planned and revised accordingly, in case of a recent functional deterioration. 


\section{MODERATE DISEASE}

\section{PNEUMONIA}

\section{RECOMMENDATION 2.1}

It is recommended to apply an individualized pulmonary rehabilitation program for the patients diagnosed with COVID-19 pneumonia when deemed appropriate after assessment.

When the first version of this guideline was published in Turkey, patients diagnosed with COVID19 pneumonia with moderate disease were mostly hospitalized. However, as the knowledge accumulated about the nature and progress of the disease and the capacity with the variety of options of health services became clearer, hospitalization criteria changed. According to recent guidelines of the Republic of Turkey, Ministry of Health ${ }^{[35]}$ most of the patients of moderate disease stay at home with the appropriate treatment plans and are followed by health personnel via telemedicine and home visits, if needed. Thus, Recommendation 2.1 should be interpreted according to the designated treatment option of the patient.

\section{For the hospitalized patient:}

- Patients without prominent respiratory difficulty and/or patients with low-level oxygen requirement ( $\leq 5 \mathrm{~L} / \mathrm{min}$ for $\mathrm{SpO}_{2} \geq 90 \%$ ), who have non-productive cough or are able to clear secretions independently do not need specific PR interventions; such as breathing strategies and bronchial hygiene techniques.

- In patients with difficulties in secretion clearance due to their respiratory or neuromuscular comorbidity (e.g., cystic fibrosis, neuromuscular disease, spinal cord injury, stroke, chronic pulmonary diseases) PR interventions for airway clearance should be applied.

- Patients who have exudative consolidation and cough with sputum, but cannot clear his/her secretions should have PR interventions for airway clearance.

- Possible progression of the disease should be taken into account and rehabilitation interventions should be withdrawn in case of high fever $\left(38^{\circ} \mathrm{C}\right)$; worsening dyspnea; respiratory rate $>30$ breaths/min; Borg dyspnea score $>3, \mathrm{SpO}_{2}<90 \%$ on oxygen therapy, respiratory distress, and other systemic symptoms such as arterial hyper/hypotension (blood pressure $[\mathrm{BP}]<90 / 60 \mathrm{mmHg}$ or $>180 / 90$
$\mathrm{mmHg}$ ), bradycardia or tachycardia (heart rate $[\mathrm{HR}]<40$ beat $/ \mathrm{min}$ or $>120$ beat $/ \mathrm{min}$ ), intercurrent arrhythmias, profuse sweating, evidence of radiological lesion progression ( $>50 \%$ ) within 24 to $48 \mathrm{~h}$ or other conditions that may be indication of clinical worsening and general contraindications for exercise. ${ }^{[36,37]}$

\section{For the patients followed at home:}

- It is recommended to apply same treatment guidelines and instructions mentioned above for the patients. Although there is no such infrastructure at the moment, the symptoms may be questioned via telemedicine (mostly phone calls, and home visits, when needed) and patients in the need of PR may be selected and further information may be supplied and supported with booklets, videos, social media applications or other available telerehabilitation methods.

All patients, either in hospital or at home, should be recommended to perform ROM and mobilization activities to the limit of fatigue and other symptoms. Pulmonary rehabilitation program may include the utilization of devices for individual use such as incentive spirometry, flutter breathing devices, positive expiratory pressure (PEP) and having sputum expelled with controlled cough and huffing maneuvers and finally breathing strategies. As these activities result in aerosol formation, necessary measures should be taken to prevent spreads to the environment (i.e., collecting the sputum in closed plastic bags, patient wearing a mask while performing breathing strategies and cough maneuvers, in negative pressurized rooms). ${ }^{[38]}$

Although aerobic exercises, respiratory and general muscle strengthening exercises were also recommended in some earlier guidelines, ${ }^{[36-41]}$ at the acute pneumonia stage, it is not recommended to routinely apply these

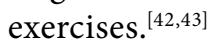

Pulmonary rehabilitation to be used at this stage is thought to help to manage problems such as dyspnea, cough and sputum, anxiety and depression; ${ }^{[44]}$ however, there are no such data in the context of evidence-based medicine for COVID-19. ${ }^{[36,37,41,45]}$

\section{RECOMMENDATION 2.2}

All patients who have prolonged immobility, frailty, multiple comorbidities such as stroke, spinal cord injury, cardiac or respiratory diseases, functional decline in daily activities should have rehabilitation interventions for breathing strategies, mobilization, and ROM exercises. 
These individuals should be evaluated by a PMR specialist and the patient's still ongoing home-based rehabilitation program should be revised or a new program should be recommended tailored to the needs of the patient, and various methods such as booklets or telemedicine can be used.

\section{RECOMMENDATION 2.3}

The use of individual devices, mobilization techniques and exercises prescribed by the PMR specialist should be instructed to the patient by one of the rehabilitation team members. These practices can be performed by PMR specialist or existing healthcare personnel (nurse, physiotherapist, occupational therapist, physiotherapy technician, etc.) depending on the present conditions, and availability of human resources and PPE at the facility. ${ }^{[46]}$ The frequency of PR interventions should be planned according to the patient's status. It is recommended to perform a regular follow-up of the rehabilitation program and revised accordingly considering the patient's clinical status.

The PR programs can be offered by the use of printed and visual materials, videos, social media, telerehabilitation in the presence of eligible infrastructure.

\section{SEVERE DISEASE}

\section{SEVERE PNEUMONIA}

\section{RECOMMENDATION 3.1}

It is recommended to plan an individualized pulmonary rehabilitation program for patients with severe COVID-19 pneumonia and to start implementing the program after the patient becomes medically stable and fulfills the following criteria:

- Initial diagnosis time or symptom onset $\geq 7$ days; initial onset of dyspnea $\geq 3$ to 5 days

- Respiratory system ${ }^{[36,37]}$

- $\mathrm{FiO}_{2} \leq 0.6$

- $\mathrm{SpO}_{2} \geq 90 \%$ on oxygen therapy

- Respiratory rate $\leq 40$ breaths/min

- PEEP $\leq 10 \mathrm{cmH}_{2} \mathrm{O}$

- Absence of ventilator resistance

- Cardiovascular system

- BP $\geq 90 / 60$ or $\leq 180 / 90 \mathrm{mmHg}$

- HR $\geq 40$ and $\leq 120$ beats/min

- Absence of new arrhythmia or myocardial ischemia
- Absence of shock with lactic acid level $\geq 4 \mathrm{mmol} / \mathrm{L}$

- Absence of new unstable deep vein thrombosis and pulmonary embolism

- Nervous system; able to cope with the rehabilitation program regarding the patient's consciousness and cognitive status.

- Others

- Absence of new progressively worsening hepatic/renal impairment

- Temperature $\leq 38^{\circ} \mathrm{C}$

After the assessment of the general condition, fever, respiratory symptoms such as dyspnea, cough, respiratory rate, $\mathrm{SpO}_{2}$, blood tests, radiological findings, ROM, respiratory and peripheral muscle strength, functional capacity, exercise capacity and other comorbid disease states, a rehabilitation program appropriate for the current impairments of the patient should be planned.

Many guidelines and expert recommendations suggest that PR should be applied to COVID-19 patients with severe pneumonia. Although it is thought that PR to be implemented during this period will help to manage symptoms such as dyspnea, cough, sputum, weaknesses of respiratory and peripheral muscles, immobilization, anxiety and depression; there is still no such data in the context of evidence-based medicine. The evidence obtained from studies evaluating the effectiveness of PR is mostly derived from research performed on individuals with chronic pulmonary diseases. ${ }^{[15,35,43,47]}$ Research related to rehabilitation in COVID-19 is still sparse. ${ }^{[48]}$ Yet, the studies mainly focus on the clinical presentation of COVID-19 rather than the efficacy of rehabilitation intervention and their level of evidence is either category 3 or $4 .{ }^{[49]}$

\section{RECOMMENDATION 3.2}

It is recommended to discontinue $\mathrm{PR}$, if the following conditions occur: ${ }^{[18,21,22,38,41,50,51]}$

- Respiratory system

- Progression in chest imaging $>50 \%$ within 24 to 48 hours

- $\mathrm{SpO}_{2}<90 \%$ or decrease by $>4 \%$ from baseline

- Respiratory rate $>40$ breaths/min

- Ventilator resistance

- Artificial airway dislodgement or migration 
- Cardiovascular system

- $\mathrm{BP}<90 / 60$ or $>180 / 90 \mathrm{mmHg}$, or $>20 \%$ change compared with baseline

- HR $<40$ or $>120$ beats/min,

- New arrhythmia and myocardial ischemia

- Nervous system

- Loss of consciousness

- Irritability

- Unable to cope with the program or follow instructions

- Others

- Body temperature $>38.0^{\circ} \mathrm{C}$

- Indication of clinical worsening and general contraindications for exercise

- Discontinuation of any treatment or removal of monitoring tube connected to the patient

- Patient-perceived heart palpitations

- Exacerbation of dyspnea or shortness of breath, and intolerable fatigue.

\section{RECOMMENDATION 3.3}

Although the PR program is individualized according to the condition of the patient, it should basically include similar techniques used in all other non-COVID-19 pneumonia types.

- During this period, the signs and findings listed in Recommendation 3.2 should be closely followed.

- Positioning in bed and frequent position changes should be made; in cases with severe pneumonia and/or using non-invasive mechanical ventilators (NIMVs), a semi-sitting or sitting position is recommended to prevent the risk of aspiration. While positioning, aids such as pillows can be used to minimize effort.

- Active or active-assisted ROM exercises can be applied.

- Mobilization as soon as possible (sitting position in bed, sitting on the edge of the bed, transfer to the chair, and standing with the help of assistive devices, such as walker, tilt table, etc.) should be ensured.

- Progressive ambulation of patients who can tolerate mobilization with the help of walking aids should be attempted.

- Airway clearance techniques should not be used in patients who have a dry cough and no sputum.
- For patients having sputum and productive cough, airway clearance techniques should be used. The patient should be taught how to expel the sputum that has accumulated and the central airways should be cleared by maneuvers such as controlled cough and huffing. Devices for personal use such as incentive spirometry, flutter breathing devices, and PEP may also be prescribed to mobilize sputum to central airways and maneuvers such as controlled cough and huffing should be repeated.

- Controlled breathing techniques including diaphragmatic breathing, alternate breathing, and pursed-lip breathing may be used. However, it should be kept in mind that the use of these techniques may increase the respiratory workload during the acute stage and further lead to deterioration of the patient's condition.

\section{RECOMMENDATION 3.4}

The use of individual devices, mobilization techniques and exercises prescribed by the PMR specialist should be instructed to the patient by one of the rehabilitation team members. These practices can be performed by PMR physician or existing healthcare personnel (nurse, physiotherapist, occupational therapist, physiotherapy technician, etc.) depending on the present conditions, and availability of human resources and PPE at the facility. ${ }^{[46]}$ The frequency of PR interventions should be planned according to the patient's status. It is recommended to perform a regular follow-up of the rehabilitation program and revised accordingly considering the patient's clinical status.

Rehabilitation interventions such as positioning, mobilization, ROM exercises can be performed by a team member. Training of PR interventions which require active participation of the patient (such as controlled breathing techniques, using of devices) should be provided by a team member, individually. PR programs may be offered by the use of printed and visual materials, videos, social media, telerehabilitation in the presence of eligible infrastructure.

\section{CRITICAL DISEASE}

\section{ACUTE RESPIRATORY DISTRESS SYNDROME}

\section{RECOMMENDATION 4.1}

Comprehensive PR in COVID-19 during ARDS is not required, but rehabilitation principles to avoid adverse effects of immobilization and for secretion management should be followed. 
Pulmonary rehabilitation is not appropriate or safe for ARDS patients in respiratory stress whose $\mathrm{PaO}_{2} / \mathrm{FiO}_{2}<300 \mathrm{mmHg}$ (on ventilator settings or $\mathrm{PEP} /$ continuous positive airway pressure (CPAP) of $\left.>5 \mathrm{cmH}_{2} \mathrm{O}\right)$, and mostly have fever $\left(>38^{\circ} \mathrm{C}\right)$, respiratory rate of $>40$ breaths/min, oxygen saturation of $<90 \%$ despite oxygen support, HR $<40$ or $>120$ beats/ min, or have variable arrhythmia, BP $<90 / 60$ or $>180 / 90 \mathrm{mmHg}$, who are in shock, deep sedation and who has radiological progression more than $50 \%$ in the last 24-48 hours. ${ }^{[21,22,38,41,50,51]}$

- Pulmonary rehabilitation is not appropriate and safe in ARDS patients who are in prone position which is preferred to increase oxygenation for 12 to 16 hours.

- During the following rehabilitation interventions, vital and respiratory stress signs should be closely monitored.

- In patients requiring secretion management, these procedures should be done in negative pressure rooms and/or isolated rooms and closed systems, as this may cause aerosol formation. Mechanical insufflator and exsufflator (MI-E) and oscillating devices, which are other airway cleaning techniques used in the intensive care, should be used very carefully considering the benefit/harm due to aerosol formation.

- Patients should be carefully inspected for pressure ulcers. Attention should be paid to the proper positioning.

- Range of motion exercises in 10-15 repetitions/ day for each joint should be performed when the patient is in the supine position. When the patients can participate, they can do active or assisted exercises.

- Mobilization exercises and self-care activities can be started when the general condition and cooperation of the patient allows.

- Electrical stimulation modalities such as NMES can be used in patients with muscle weakness for large muscle groups at an intensity that will not cause any burns.

\section{RECOMMENDATION 4.2}

The patient who is recovering and/or in the weaning period should be evaluated together with the PMR physician and the ICU physicians about the eligibility and the timing of rehabilitation. If the patient fulfills the eligibility criteria for PR (Recommendation 3.1 and 3.2) the recommendations for COVID-19 patients with severe pneumonia should be followed.

\section{RECOMMENDATION 4.3}

After the critical disease and ICU period, the patient who has functional limitations, such as difficulty in mobility or other activities of daily living, and persistent symptoms should be evaluated and a patient-specific rehabilitation program is planned by the PMR specialist.

During the evaluation process, the general condition of the patient, the blood tests, radiological findings, respiratory parameters, joint ROM, muscle strength, respiratory muscle strength, activities of daily living, functional capacity and other existing comorbid conditions are considered. At this transition stage, respiratory muscle exercises (inspiratory muscle training, expiratory muscle training), breathing strategies (controlled breathing techniques, airway clearance techniques) and aerobic training, progressive resistive exercises and shoulder girdle and upper extremity exercises can be progressively recommended only if the patient's status allows. For PR, criteria outlined in above recommendations should be followed.

\section{PULMONARY REHABILITATION AFTER COVID-19}

\section{RECOMMENDATION 5.1}

Comprehensive PR is indicated for individuals with ongoing fatigue, respiratory symptoms, diminished activities of daily living, reduced exercise tolerance, and limited functionality 6 to 8 weeks following discharge.

As of April 15 th, 2021 , the number of individuals infected with SARS-CoV-2 virus over the world exceeded 136 million. At the beginning of the pandemic, COVID-19 was thought of as a disease that affects primarily the pulmonary system. Soon after, it has been understood that, it is a multisystem disease with complications affecting the cardiac, renal, gastrointestinal, nervous, endocrine and musculoskeletal systems. However, pulmonary involvement still remains significant. A more serious prognosis is expected in patients who have complications related to pulmonary involvement. In many studies, prolonged symptoms of fatigue, dyspnea and breathlessness are reported in patients besides symptoms related to other systems. ${ }^{[52-54]}$ These complications, particularly pulmonary related problems, have the potential to impair the patient's quality of life by limiting their daily living activities, 
and reduce exercise capacity. Thus, all these reveal the need for comprehensive PR in patients after COVID-19.

The current guidance for routine postexacerbation PR for COPD is 4 weeks post discharge; however, the recommendation to delay $\mathrm{PR}$ for COVID-19 patients until 6 to 8 weeks post-discharge was based upon the following considerations. First, there is a lack of data about the decay of the levels of infection in the COVID-19 survivor. Second, there is data suggesting that, a proportion of physical recovery will have occurred in ARDS survivals in two months. ${ }^{[55]}$ Also, it may be a burden for services to recruit patients at an earlier time after discharge. ${ }^{[56]}$ Hospitalized patient with COVID-19 including the survivors of acute respiratory failure should be evaluated at 6 to 8 weeks following hospital discharge. Multiple re-assessments may be required at different time points such as 3 and 6 months after discharge, and a PR program can be initiated according to the individual needs of the patient.

\section{RECOMMENDATION 5.2}

Patients who exhibit signs of respiratory impairment whether accompanying musculoskeletal, swallowing, functional, cognitive or psychosocial problems exist or not are the main candidates for a comprehensive PR program. A detailed information on comprehensive $P R$ program exists in the introduction section.

Particular attention should be paid to the following criteria:

1. Patients who have been treated in the ICU either with or without IMV.

2. Patients who needed high level of oxygen therapy and who have been treated with or without non-invasive ventilation.

3. Patients with persisting respiratory symptoms and diminished respiratory function due to COVID-19 either treated in hospital or at home.

4. Individuals with special conditions (older age, immunocompromised, having neurological, pulmonary, cardiovascular, metabolic and other systemic diseases etc.).

PR candidates may also have:

1. Joint contractures, muscle weakness, physical deconditioning

2. Widespread pain
3. Limitation in activities of daily living

4. Neurological conditions and complications due to COVID-19 such as critical-illness neuromyopathy, stroke, tremor

5. Cardiac conditions and complications due to COVID-19

6. Swallowing and communication impairments

7. Psychosocial impairments

8. Impaired quality of life

Patients with the following criteria should be excluded:

1. Patients with suspected active COVID-19 infection.

2. Patients who predominantly have unstable systemic problems such as neurological, cardiac, renal etc. due to COVID-19.

3. Patients with musculoskeletal difficulties that preclude exercise (e.g., severe arthritis or severe peripheral vascular disease).

4. Patients with severe frailty in the need of palliative care.

5. General contraindications for PR such as angina pectoris, recent myocardial infarction, severe pulmonary hypertension, congestive heart failure, unstable diabetes, inability to do exercise due to orthopedic or other reasons, psychiatric illness, dementia, cognitive dysfunction. ${ }^{[57]}$

6. Severe exercise-induced hypoxemia which cannot be corrected with $\mathrm{O}_{2}$ supplementation.

7. Lack of motivation, non-adherence, unwilling to give consent.

PR program should be withdrawn or adjusted in the following conditions:

1. Body temperature $>37.2^{\circ} \mathrm{C}$ at rest ${ }^{[58]}$

2. Worsening dyspnea

3. Borg dyspnea score $>3$ at rest

4. Exercise is interrupted if the patient develops severe dyspnea (eg, Borg score $\geq 7)^{[59]}$

5. Respiratory rate $>30$ breaths/min at rest

6. Resting $\mathrm{SpO}_{2}<90 \%$ on oxygen therapy

7. Oxygen should be supplemented or titrated when $\mathrm{SpO}_{2}<88 \%$ or a relative reduction of $2 \%-5 \%$ occurs ${ }^{[59]}$

8. Resting BP $<90 / 60$ or $>180 / 90 \mathrm{mmHg}$

9. Resting $\mathrm{HR}<40$ or $>120$ beat $/ \mathrm{min}$ 
10. Intercurrent arrhythmias

11. Other conditions that may be indication of clinical worsening and general contraindications for exercise.

\section{RECOMMENDATION 5.3}

Comprehensive PR should be applied in a wellappointed PR setting. After the assessment and program prescription by the PMR physician, an approach can be made with a core rehabilitation team consisting of PMR physician, nurse, physiotherapist and occupational therapist, as well as with a wider rehabilitation team including psychologist, nutritionist, speech and swallowing therapist, etc. according to the identified deficits and problems of the patient.

Although the core rehabilitation team is mostly sufficient, individualized protocols with expanded, systematic and organized determinants are one of the most important steps of a successful PR.

\section{RECOMMENDATION 5.4}

The PR setting for the post-COVID-19 patients should be chosen based on the clinical status, existing impairments and characteristics of the patients.

Inpatient rehabilitation may be indicated in patients with tracheostomy, CPAP or bilevel positive airway pressure (BIPAP) therapy, requiring high levels of oxygen therapy at rest, extra-pulmonary comorbidities or severe limitations in the activities of daily life. $\mathrm{PR}$ as an outpatient setting may be appropriate for the patients who are sufficient to handle their daily activities and without transportation limitations. A home setting may be used in clinically stable patients and who do not require monitorization by a health professional during sessions.

The delivery of PR program may vary due to the PR setting and the ongoing risk of contagiousness such as the usual face-to-face intervention, visual tools including brochures, booklets, and telemedicine interventions. Since telerehabilitation is a novel approach for many healthcare facilities, special considerations should be taken into account for the implementation of PR via telerehabilitation. In patients who are appropriate for home-based PR, telerehabilitation could be used, when there is a need for social distancing, there are accessibility, transportation or cost issues, or there is no available PR program. For the implementation of telerehabilitation, there should be sufficient technological set-up both at the facility and the patient's home and adequate caregiver support if needed; the patient should be capable of understanding and following instructions via technological means, and vital parameters $\left(\mathrm{SpO}_{2}, \mathrm{HR}, \mathrm{BP}\right.$, respiratory rate) and the symptoms should be recorded by the patient/ caregiver before the telerehabilitation session, and informed and monitored.

\section{RECOMMENDATION 5.5}

The patients should be questioned to ensure that they do not have any symptoms of recurrent COVID-19 and any of the exclusion criteria for PR before the assessment and rehabilitation program.

In case they have symptoms of COVID-19, they should be advised to self-isolate for 10 days or in line with the current guidance. If there are no symptoms indicating a new infection, patient can start the program. The contagiousness of COVID-19 is shown to be lasting up to 10 days usually and up to 30 days in some severe cases. Since the assessments and rehabilitation program are planned to be performed 6 to 8 weeks after the discharge, there is no need for swab testing unless recurrent/new infection is suspected. Currently, results of antibody testing should not change the program planning.

\section{RECOMMENDATION 5.6}

All patients should be thoroughly assessed as recommended by the $P R$ guidelines before the $P R$ program, and multi-system examination using biopsychosocial approach should be performed considering the various impacts of COVID-19, as well.

Assessments are done mainly on six domains:

1. Symptoms

a. Dyspnea (e.g., rated perceived exertion by Borg, or Medical Research Council).

b. Fatigue

c. Pain

d. Weakness

2. Pulmonary function testing

3. Physical capacity assessment

a. Exercise test/Cardiopulmonary exercise test (ET/CPET)

b. Field tests of exercise (e.g., 2-min/6-min walk tests; shuttle test)

c. Peripheral and inspiratory muscle strength ${ }^{[60]}$

d. Balance 
4. Functionality

a. Activities of daily living; (e.g., PostCOVID-19 Functional Status Scale, Barthel, Functional Independence Measure-FIM, Katz Index of Independence in Activities of Daily Living)

b. Bedside assessments (e.g., Chelsea Physical Assessment Tool, Short Physical Performance Battery Test, sit-to-stand test). ${ }^{[61]}$

5. Psychological status

a. Hospital Anxiety Depression Scale, Beck Depression Inventory/Beck Anxiety Inventory, etc.

6. Quality of life

a. EuroQol-5 Dimension (EQ-5D), St. George's Respiratory Questionnaire (SGRQ), etc.

According to the severity of the disease and length of hospitalization, there may be symptoms and impairments other than those of the respiratory system. Therefore, each patient's further evaluation should be individual based on the existing impairments and symptoms and may include nutritional, cognitive, orofacial including swallowing and speech, systemic, particularly cardiac and neurological assessments. Vocational assessment and returning to work strategies should be also considered.

\section{RECOMMENDATION 5.7}

During the assessments and rehabilitation program, guidelines should be followed regarding the prevention of spread of the disease such as social distancing, hygiene of the patient and the facility, even if the patient is considered to be noncontagious.

All HCWs involving in the PR process of COVID-19 patients should wear appropriate PPE using proper techniques to avoid selfcontamination. Even if the patients considered to be non-contagious, eye protection, donning of gloves and disposable gown besides face masks should be used during aerosol-generating procedures. All patients should wear surgical masks during rehabilitation. If possible, exercise testing rooms should be equipped with negative pressure systems and HEPA filters. Otherwise, exercise testing rooms should be aerated well after each patient and there should be at least 30 min between two patients' tests and assessments. All surfaces should be sanitized after each patient's assessment and rehabilitation session. A unique set of principles should be implemented for the exercise areas, as well. The number of patients rehabilitated at the same time should be limited to allow social distancing and depends on the field's size. The waiting room and appointments should be arranged accordingly to ensure necessary social distancing.

\section{The Strengths of the Guideline}

The number of COVID-19 cases in our country has been increasing, similar to the world. This guideline is prepared by taking the health practices in our country into consideration. It aims to provide guidance primarily to PMR specialists and to all physicians. PMR specialists taking part in the development of this guideline are experienced in PR and they rehabilitate COVID-19 patients in both acute and chronic stages in different hospitals across Turkey. Some have gained experiences in treating COVID-19 patients as their primary physicians, as well. This guideline will create an opportunity for sharing experiences in line with COVID-19 treatment guidelines.

\section{The Limitations of the Guideline}

This guideline was prepared with the aim of incorporating the principles of PR with scientific data pertaining to the COVID-19 pandemic which has started nearly a year ago. Although the knowledge and experience about rehabilitation in acute COVID-19 have accumulated, scientific quality is not adequate for a strong level of evidence. Yet, research concerning rehabilitation outcomes on chronic COVID-19 symptoms inlong term or outcomes of tele-rehabilitation are still scarce in number. Recommendations may need adaptations according to the condition of the patients, available resources and experience of the healthcare professionals.

\section{The Time and Method for Revision}

Following the publication of this second version of the guideline, we aim at revising it, if new evidence about the PR emerges and after evaluating the results of clinical applications and long-term results of the patients within a period of 6 to 12 months.

\section{Acknowledgement}

We would like to thank to the PMR specialists who participated in the Delphi round for the development of Recommendation 5, namely Koray Aydemir, Sibel Başaran, Sibel Çağlar, Gülin Fındıkoğlu, İsmail Güneş Gökmen, Gülçin Kaymak Karataş, Nur Kesiktaş, Serap Tomruk Sütbeyaz, Hanife Baykal Şahin, and Zeynep Turan. 


\section{Declaration of conflicting interests}

The authors declared no conflicts of interest with respect to the authorship and/or publication of this article.

\section{Funding}

The authors received no financial support for the research and/or authorship of this article.

\section{REFERENCES}

1. Huang C, Wang Y, Li X, Ren L, Zhao J, Hu Y, et al. Clinical features of patients infected with 2019 novel coronavirus in Wuhan, China. Lancet 2020;395:497-506.

2. Müdürlüğü TCSBHSG. COVID-19 (SARS-CoV-2 Enfeksiyonu). T.C. Sağlık Bakanlığı 2020. Erişim linki: https://covid19.saglik.gov.tr/TR-66337/genel-bilgilerepidemiyoloji-ve-tani.html. [Erişim tarihi: December 07, 2020].

3. World Health Organization. COVID-19 Clinical Management - Living Guidance - 25 January 2021. 2021.

4. Jia HP, Look DC, Shi L, Hickey M, Pewe L, Netland J, et al. ACE2 receptor expression and severe acute respiratory syndrome coronavirus infection depend on differentiation of human airway epithelia. J Virol 2005;79:14614-21.

5. Wan Y, Shang J, Graham R, Baric RS, Li F. Receptor recognition by the novel coronavirus from Wuhan: An analysis based on decade-long structural studies of SARS coronavirus. J Virol 2020;94:e00127-20.

6. Donoghue M, Hsieh F, Baronas E, Godbout K, Gosselin M, Stagliano N, et al. A novel angiotensin-converting enzymerelated carboxypeptidase (ACE2) converts angiotensin I to angiotensin 1-9. Circ Res 2000;87:E1-9.

7. Ejaz H, Alsrhani A, Zafar A, Javed H, Junaid K, Abdalla AE, et al. COVID-19 and comorbidities: Deleterious impact on infected patients. J Infect Public Health 2020;13:1833-9.

8. Wu C, Chen X, Cai Y, Xia J, Zhou X, Xu S, et al. Risk factors associated with acute respiratory distress syndrome and death in patients with coronavirus disease 2019 pneumonia in Wuhan, China. JAMA Intern Med 2020;180:934-43.

9. Tzotzos SJ, Fischer B, Fischer H, Zeitlinger M. Incidence of ARDS and outcomes in hospitalized patients with COVID19: A global literature survey. Crit Care 2020;24:516.

10. Fox SE, Akmatbekov A, Harbert JL, Li G, Quincy Brown J, Vander Heide RS. Pulmonary and cardiac pathology in African American patients with COVID-19: An autopsy series from New Orleans. Lancet Respir Med 2020;8:681-6.

11. Shaw B, Daskareh M, Gholamrezanezhad A. The lingering manifestations of COVID-19 during and after convalescence: Update on long-term pulmonary consequences of coronavirus disease 2019 (COVID-19). Radiol Med 2021;126:40-6.

12. COVID-19 vaccine development pipeline. Vaccine Centre, London School of Hygiene and Tropical Medicine. Available at: https://vac-lshtm.shinyapps.io/ncov_vaccine_ landscape/. [Accessed: March 10, 2021]

13. Lurie N, Saville M, Hatchett R, Halton J. Developing Covid-19 vaccines at pandemic speed. N Engl J Med 2020;382:1969-73.
14. T.C. Sağlık Bakanlığı Genel Müdürlüğü. Ağır Pnömoni, ARDS, Sepsis ve Septik Şok Yönetimi. T. C. Sağlik Bakanlığı: 2020. https://covid19.saglik.gov.tr/TR-66340/ agir-pnomoni-ards-sepsis-ve-septik-sok-yonetimi.html. [Erişim tarihi: October 23, 2020].

15. Spruit MA, Singh SJ, Garvey C, ZuWallack R, Nici L, Rochester C, et al. An official American Thoracic Society/ European Respiratory Society statement: Key concepts and advances in pulmonary rehabilitation. Am J Respir Crit Care Med 2013;188:e13-64.

16. Güell Rous MR, Díaz Lobato S, Rodríguez Trigo G, Morante Vélez F, San Miguel M, Cejudo P, et al. Pulmonary rehabilitation. Sociedad Española de Neumología y Cirugía Torácica (SEPAR). Arch Bronconeumol 2014;50:332-44.

17. Botana Rial M, Briones Gómez A, Ferrando Gabarda JR, Cifuentes Ruiz JF, Guarín Corredor MJ, Manchego Frach $\mathrm{N}$, et al. Tru-cut needle pleural biopsy and cytology as the initial procedure in the evaluation of pleural effusion. Arch Bronconeumol 2014;50:313-7.

18. T.C. Sağlık Bakanlı̆̆ı. COVID-19 Rehberi. 2020. Erişim linki: https://covid19.saglik.gov.tr/TR-66301/covid-19rehberi.html [Erişim tarihi: 17 Mart 2021].

19. World Health Organization. Rational use of personal protective equipment for coronavirus disease (COVID-19) and considerations during severe shortages. Interim Guidance. 2020. Available at: https://www.who.int/publications/i/ item/rational-use-of-personal-protective-equipment-forcoronavirus-disease-(covid-19)-and-considerations-duringsevere-shortages. [Accessed: December 23, 2020].

20. T.C. Sağlık Bakanlığı. COVID-19 Pandemisinde Sağlık Kurumlarında Çalışma Rehberi ve Enfeksiyon Kontrol Önlemleri. Ankara: T.C. Sağlık Bakanlığı; 2021. s. 176.

21. Lazzeri M, Lanza A, Bellini R, Bellofiore A, Cecchetto S, Colombo A, et al. Respiratory physiotherapy in patients with COVID-19 infection in acute setting: A Position Paper of the Italian Association of Respiratory Physiotherapists (ARIR). Monaldi Arch Chest Dis 2020;90.

22. Thomas P, Baldwin C, Bissett B, Boden I, Gosselink $\mathrm{R}$, Granger CL, et al. Physiotherapy management for COVID-19 in the acute hospital setting: Clinical practice recommendations. J Physiother 2020;66:73-82.

23. Cardiopulmonary Rehabilitation Study Group of Turkish Society of Physical Medicine and Rehabilitation Specialists. COVID-19 Sonrası pulmoner rehabilitasyon. Istanbul: Turkish Society of Physical Medicine and Rehabilitation Specialists; 2020.

24. Kurtaiş Aytür Y, Köseoğlu BF, Özyemişçi Taşkıran Ö, Ordu-Gökkaya NK, Ünsal Delialioğlu S, Sonel Tur B, et al. Pulmonary rehabilitation principles in SARSCOV-2 infection (COVID-19): A guideline for the acute and subacute rehabilitation. Turk J Phys Med Rehabil 2020;66:104-20.

25. Brouwers MC, Kho ME, Browman GP, Burgers JS, Cluzeau F, Feder G, et al. Development of the AGREE II, part 1: Performance, usefulness and areas for improvement. CMAJ 2010;182:1045-52.

26. Richardson WS, Wilson MC, Nishikawa J, Hayward RS. The well-built clinical question: A key to evidence-based decisions. ACP J Club 1995;123:A12-3. 
27. World Health Organization. Support for Rehabilitation Self-Management after COVID-19-Related Illness. Geneva: World Health Organization; 2020.

28. American College of Sports Medicine. ACSM's Guidelines for Exercise Testing and Prescription. 10th ed. Philadelphia: Lippincott Williams \& Wilkins; 2018.

29. Nathens AB, Neff MJ, Jurkovich GJ, Klotz P, Farver $\mathrm{K}$, Ruzinski JT, et al. Randomized, prospective trial of antioxidant supplementation in critically ill surgical patients. Ann Surg 2002;236:814-22.

30. Hanson C, Lyden E, Rennard S, Mannino DM, Rutten EP, Hopkins R, et al. The relationship between dietary fiber intake and lung function in the national health and nutrition examination surveys. Ann Am Thorac Soc 2016;13:643-50.

31. Patel V, Dial K, Wu J, Gauthier AG, Wu W, Lin M, et al. Dietary antioxidants significantly attenuate hyperoxiainduced acute inflammatory lung injury by enhancing macrophage function via reducing the accumulation of airway HMGB1. Int J Mol Sci 2020;21:977.

32. Fowler AA 3rd, Truwit JD, Hite RD, Morris PE, DeWilde C, Priday A, et al. Effect of vitamin C infusion on organ failure and biomarkers of inflammation and vascular injury in patients with sepsis and severe acute respiratory failure: The CITRISALI randomized clinical trial. JAMA 2019;322:1261-70.

33. Mahmoodpoor A, Hamishehkar H, Shadvar K, Ostadi Z, Sanaie S, Saghaleini SH, et al. The effect of intravenous selenium on oxidative stress in critically ill patients with acute respiratory distress syndrome. Immunol Invest 2019;48:147-59.

34. Boudreault F, Pinilla-Vera M, Englert JA, Kho AT, Isabelle $\mathrm{C}$, Arciniegas AJ, et al. Zinc deficiency primes the lung for ventilator-induced injury. JCI Insight 2017;2:e86507.

35. Ambrosino N, Clini EM. Response to pulmonary rehabilitation: Toward personalised programmes? Eur Respir J 2015;46:1538-40.

36. Wang TJ, Chau B, Lui M, Lam GT, Lin N, Humbert S. Physical medicine and rehabilitation and pulmonary rehabilitation for COVID-19. Am J Phys Med Rehabil 2020;99:769-74.

37. Yang LL, Yang T. Pulmonary rehabilitation for patients with coronavirus disease 2019 (COVID-19). Chronic Dis Transl Med 2020;6:79-86.

38. Vitacca M, Carone M, Clini EM, Paneroni M, Lazzeri M, Lanza A, et al. Joint statement on the role of respiratory rehabilitation in the COVID-19 crisis: The Italian position paper. Respiration 2020;99:493-9.

39. Spruit MA, Holland AE, Singh SJ, Tonia T, Wilson KC, Troosters T. COVID-19: Interim guidance on rehabilitation in the hospital and post-hospital phase from a European Respiratory Society and American Thoracic Societycoordinated International Task Force. Eur Respir J 2020;56:2002197.

40. BTS Guidance for pulmonary rehabilitation - Reopening services for the 'business as usual' participants. 2020. Available at: https:/www.brit-thoracic.org.uk/covid-19/ covid-19-resumption-and-continuation-of-respiratoryservices/\#pulmonary-rehabilitation [Accessed: July 30, 2020].
41. Zhao HM, Xie YX, Wang C; Chinese Association of Rehabilitation Medicine; Respiratory Rehabilitation Committee of Chinese Association of Rehabilitation Medicine; Cardiopulmonary Rehabilitation Group of Chinese Society of Physical Medicine and Rehabilitation. Recommendations for respiratory rehabilitation in adults with coronavirus disease 2019. Chin Med J (Engl) 2020;133:1595-602.

42. Bott J, Blumenthal S, Buxton M, Ellum S, Falconer C, Garrod $\mathrm{R}$, et al. Guidelines for the physiotherapy management of the adult, medical, spontaneously breathing patient. Thorax 2009;64 Suppl 1:i1-51.

43. Bolton CE, Bevan-Smith EF, Blakey JD, Crowe P, Elkin SL, Garrod R, et al. British Thoracic Society guideline on pulmonary rehabilitation in adults. Thorax 2013;68 Suppl 2:ii1-30.

44. Valenza MC, Valenza-Peña G, Torres-Sánchez I, González-Jiménez E, Conde-Valero A, Valenza-Demet G. Effectiveness of controlled breathing techniques on anxiety and depression in hospitalized patients with COPD: A randomized clinical trial. Respir Care 2014;59:209-15.

45. Li Z, Zheng C, Duan C, Zhang Y, Li Q, Dou Z, et al. Rehabilitation needs of the first cohort of post-acute COVID-19 patients in Hubei, China. Eur J Phys Rehabil Med 2020;56:339-44.

46. Resmi Gazete. Hemşirelik Yönetmeliğinde Değişiklik Yapılmasına Dair Yönetmelik. Ankara: 2011. Erişim linki: https://www.resmigazete.gov.tr/eskiler/2011/04/20110419-5. htm. [Erişim tarihi: 18 Mart 2021]

47. Chinese Association of Rehabilitation Medicine; Respiratory Rehabilitation Committee of Chinese Association of Rehabilitation Medicine; Cardiopulmonary Rehabilitation Group of Chinese Society of Physical Medicine and Rehabilitation. Recommendations for respiratory rehabilitation of coronavirus disease 2019 in adult. Zhonghua Jie He He Hu Xi Za Zhi 2020;43:308-14.

48. Ozyemisci Taskiran O, Turan Z, Tekin S, Senturk E, Topaloglu M, Yurdakul F, et al. Physical rehabilitation in intensive care unit in acute respiratory distress syndrome patients with COVID-19. Eur J Phys Rehabil Med 2021. [Online ahead of print]

49. Negrini F, de Sire A, Andrenelli E, Lazzarini SG, Patrini M, Ceravolo MG; International Multiprofessional Steering Committee of Cochrane Rehabilitation REH-COVER action. Rehabilitation and COVID-19: A rapid living systematic review 2020 by Cochrane Rehabilitation Field. Update as of October 31st, 2020. Eur J Phys Rehabil Med 2021;57:166-70.

50. Liang T, editor. Handbook of COVID-19 prevention and treatment. The First Affiliated Hospital Zhejiang University School of Medicine compiled according to clinical experience. 2020. E-book. Available at: http://www.zju.edu. cn/english/2020/0323/c19573a1987520/page.htm [Accessed: March 18, 2021].

51. Yang F, Liu N, Hu JY, Wu LL, Su GS, Zhong NS, et al. Pulmonary rehabilitation guidelines in the principle of $4 \mathrm{~S}$ for patients infected with 2019 novel coronavirus (2019-nCoV). Zhonghua Jie $\mathrm{He} \mathrm{He} \mathrm{Hu}$ Xi Za Zhi 2020;43:180-2. 
52. Puntmann VO, Carerj ML, Wieters I, Fahim M, Arendt C, Hoffmann J, et al. Outcomes of cardiovascular magnetic resonance imaging in patients recently recovered from coronavirus disease 2019 (COVID-19). JAMA Cardiol 2020;5:1265-73.

53. Carfì A, Bernabei R, Landi F; Gemelli Against COVID19 Post-Acute Care Study Group. Persistent symptoms in patients after acute COVID-19. JAMA 2020;324:603-5.

54. Halpin SJ, McIvor C, Whyatt G, Adams A, Harvey O, McLean Let al. Postdischarge symptoms and rehabilitation needs in survivors of COVID-19 infection: A cross-sectional evaluation. J Med Virol 2021;93:1013-22.

55. Gandotra S, Lovato J, Case D, Bakhru RN, Gibbs K, Berry $\mathrm{M}$, et al. Physical function trajectories in survivors of acute respiratory failure. Ann Am Thorac Soc 2019;16:471-7.

56. Jones SE, Green SA, Clark AL, Dickson MJ, Nolan AM, Moloney $\mathrm{C}$, et al. Pulmonary rehabilitation following hospitalisation for acute exacerbation of COPD: Referrals, uptake and adherence. Thorax 2014;69:181-2.

57. Hill NS. Pulmonary rehabilitation. Proc Am Thorac Soc 2006;3:66-74.

58. Demeco A, Marotta N, Barletta M, Pino I, Marinaro C, Petraroli A, et al. Rehabilitation of patients postCOVID-19 infection: A literature review. J Int Med Res 2020;48:300060520948382.

59. Celli BR. Pulmonary rehabilitation. 2020. Available at: https://www.uptodate.com/contents/ pulmonary-rehabilitation?search $=$ pulmonary $\% 20$ rehabilitation\&source $=$ search_ result\&selectedTitle $=1 \sim 97$ \&usage_type $=$ default\&display_rank=1. [Accessed: March $18,2021]$

60. Turan Z, Topaloglu M, Ozyemisci Taskiran O. Medical Research Council-sumscore: A tool for evaluating muscle weakness in patients with post-intensive care syndrome. Crit Care 2020;24:562.

61. de Sire A, Giray E, Ozyemisci Taskiran O. Chelsea physical assessment tool for evaluating functioning in post-intensive care unit COVID-19 patients. J Med Virol 2021;93:2620-2.

62. Chen N, Zhou M, Dong X, Qu J, Gong F, Han Y, et al. Epidemiological and clinical characteristics of 99 cases of 2019 novel coronavirus pneumonia in Wuhan, China: A descriptive study. Lancet 2020;395:507-13.

63. Wang D, Hu B, Hu C, Zhu F, Liu X, Zhang J, et al. Clinical characteristics of 138 hospitalized patients with 2019 novel coronavirus-infected pneumonia in Wuhan, China. JAMA 2020;323:1061-9.

64. Guan WJ, Ni ZY, Hu Y, Liang WH, Ou CQ, He JX, et al. Clinical characteristics of coronavirus disease 2019 in China. N Engl J Med 2020;382:1708-20.

65. Spinato G, Fabbris C, Polesel J, Cazzador D, Borsetto D, Hopkins C, et al. Alterations in smell or taste in mildly symptomatic outpatients with SARS-CoV-2 infection. JAMA 2020;323:2089-90.

66. Giacomelli A, Pezzati L, Conti F, Bernacchia D, Siano M, Oreni L, et al. Self-reported olfactory and taste disorders in patients with severe acute respiratory coronavirus 2 infection: A cross-sectional study. Clin Infect Dis 2020;71:889-90.

67. Tong JY, Wong A, Zhu D, Fastenberg JH, Tham T. The prevalence of olfactory and gustatory dysfunction in COVID-19 patients: A systematic review and meta-analysis. Otolaryngol Head Neck Surg 2020;163:3-11.

68. Arons MM, Hatfield KM, Reddy SC, Kimball A, James A, Jacobs JR, et al. Presymptomatic SARS-CoV-2 infections and transmission in a skilled nursing facility. N Engl J Med 2020;382:2081-90.

69. McMichael TM, Currie DW, Clark S, Pogosjans S, Kay M, Schwartz NG, et al. Epidemiology of Covid-19 in a longterm care facility in King County, Washington. N Engl J Med 2020;382:2005-11.

70. Tay HS, Harwood R. Atypical presentation of COVID-19 in a frail older person. Age Ageing 2020;49:523-4.

71. Elshafeey F, Magdi R, Hindi N, Elshebiny M, Farrag N, Mahdy S, et al. A systematic scoping review of COVID-19 during pregnancy and childbirth. Int J Gynaecol Obstet 2020;150:47-52.

72. CDC COVID-19 Response Team. Coronavirus disease 2019 in children - United States, February 12-April 2, 2020. MMWR Morb Mortal Wkly Rep 2020;69:422-6.

73. World Health Organization. IMAI District Clinician Manual: Hospital Care for Adolescents and Adults. In: Guidelines for the management of common illnesses with limited resources Switzerland: World Health Organization; 2011.

74. ARDS Definition Task Force, Ranieri VM, Rubenfeld GD, Thompson BT, Ferguson ND, Caldwell E, et al. Acute respiratory distress syndrome: The Berlin Definition. JAMA 2012;307:2526-33.

75. Khemani RG, Smith LS, Zimmerman JJ, Erickson S; Pediatric Acute Lung Injury Consensus Conference Group. Pediatric acute respiratory distress syndrome: Definition, incidence, and epidemiology: Proceedings from the Pediatric Acute Lung Injury Consensus Conference. Pediatr Crit Care Med 2015;16(5 Suppl 1):S23-40.

76. Riviello ED, Kiviri W, Twagirumugabe T, Mueller A, Banner-Goodspeed VM, Officer L, et al. Hospital incidence and outcomes of the acute respiratory distress syndrome using the Kigali Modification of the Berlin Definition. Am J Respir Crit Care Med 2016;193:52-9.

77. Rhodes A, Evans LE, Alhazzani W, Levy MM, Antonelli M, Ferrer R, et al. Surviving sepsis campaign: International guidelines for management of sepsis and septic shock: 2016. Intensive Care Med 2017;43:304-77.

78. Weiss SL, Peters MJ, Alhazzani W, Agus MSD, Flori HR, Inwald DP, et al. Surviving sepsis campaign international guidelines for the management of septic shock and sepsisassociated organ dysfunction in children. Intensive Care Med 2020;46(Suppl 1):10-67.

79. World Health Organization. Country \& technical guidance - coronavirus disease (COVID-19). Geneva: World Health Organization; 2020. 